\title{
English-speaking Astrological Discourse as a Part of Esoteric Discourse and its Nominations
}

\author{
Olga Sapova ${ }^{1}$ \\ Liliya Stoikovich² \\ 1. Samara State University of Economics, Russia, 443090, Samara, Sovetskoi Armii Street, 141 \\ 2. Samara State University of Economics, Russia, 443090, Samara, Sovetskoi Armii Street, 141 \\ Correspondence: Olga Sapova, Samara State University of Economics, 443090, Russia \\ Samara, Sovetskoi Armii Street, 141, Email: sseu.international@gmail.com
}

\section{Doi:10.5901/mjss.2015.v6n6s3p450}

\begin{abstract}
Article is devoted to some aspects of an English-speaking astrological discourse (linguistic, cognitive) and to its studying prospects. The objective of this article is to describe nominative tools of esoteric discourse from the point of view of its etymology, semantics and word - formation. In this article the etymological analysis of original and adopted nominations of esoteric discourse is given. It has been concluded that archaic words are coming into use together with reviving kinds of esoteric practices and a keen interest of a modern person. The author does an attempt to define a place of an astrological discourse among other discourse types, its ratio with esoteric and predictive discourses, considers its features, components, participants and their relationship.
\end{abstract}

Keywords: esoteric discourse, astrological discourse, etymological analysis, semantic analysis, esoteric discourse nominations.

\section{Introduction}

In modern linguistics the discursive direction is one of priority and covers the widest range of discourses. Works of modern linguists [Karasik V. I., Makarov M. V., Van Dyck, Kashkin V. B., Savitskayte E.R., Knyazeva A.A., Stoykovich G. V., Klyushina A.M. etc.] are devoted to the theory of discourse and research of different discourse types. At the same time, a number of discourses remains out of linguists sight. We can refer to such discourses a so-called astrological discourse which, in our opinion, did not receive sufficient coverage in linguistics.

Relevance of discourse theory development, studying of different discourse types increase in conditions of scientific paradigm change, appeal to complex discourse studying as difficult multidimensional phenomenon of national culture, in conditions of strengthening attention to an anthropocentric factor in language that is specified by a new person position, his psychological-emotional state in difficult modern changing world. The set of problems, big psychological pressure force a modern person to look for answers to the questions, ways of success achievement, self-improvement in different ways, including not quite traditional ways, which take you away from reality. In this regard in the last decades esoteric discourse spread and developed well. This type of discourse even more often draws researchers attention, however it is not fully described both in linguistics in general, and on material of English language.

In all times a person showed a keen interest in issues concerning his future, his family, his country future and in a global sense, mankind future. The problem of forecasting interested and still interests different minds from a simple person - an individual - to scientists and top-level politicians. Thus since ancient times in society there were those who creates different types of predictive texts: predictors, astrologers, chiromantists, numerologists, etc. These kinds of activity are often united by the terms "esoterics", "esoteric" which are interpreted differently. Esoterics in a broad sense is defined as knowledge about oneself and world secrets.

Astrology, magic, meditation, mysticism, clairvoyance, parapsychology, numerology: all these concepts are united by mystical outlook basis which is on an antipole from scientific outlook: the science is based on empirical, reproduced data - axioms, and mysticism is based on incognizable, uncertain concepts. However this uncertainty, unknowingness especially attracts a person who is always trying to know something. Without supporting ideologically one of stated positions, we put the task to study linguistic and cognitive characteristics of this discourse.

Certainly, this specific area of human activity reflects in the language and is realized in oral and written texts combined in an esoteric discourse with its own distinctive structural, substantial, pragmatical, communicative, cognitive, 
linguistic-cultural and other characteristics. The astrological discourse which is a part of an esoteric discourse, and also a predictive discourse which is partially described in linguistics [Savitskayte 2006, Knyazeva 2009] is of great interest for us. So, we consider an astrological discourse as interdiscursive formation combining lines of esoteric and predictive discourses. The astrological discourse is an integral part of communication, its analysis allows to discover deep language characteristics, human thinking and it is of special interest to linguistic studying of this institutional discourse structure (according to V. I. Karasik's classification (Karasik 2002)).

\section{Research Methods}

English-speaking astrological discourse reflects a certain part of world picture and, in our opinion, has ethnolinguistic specifics that also represents a great interest for studying. It reflects a certain part of world picture which material form is language. In the language it is embodied first of all in relevant texts. Now there is a big variety of texts which have astrological character in cultural English space. Their considerable share is made by the texts containing different horoscopes. Studying of horoscopes texts typology in English, their structural, substantial, pragmatical and other characteristics is obviously an important stage of studying of esoteric/predictive/astrological discourse in general. In all variety of predictive directions, astrological has a broad application and often serves to define different types of forecasts. In this regard in our work the term "astrological" (in the absence of another generalizing term) is used both in a broad sense (a prediction on a mystical outlook basis), and in narrow sense (a prediction on the basis of star- planetary arrangement).

The main function of a horoscope is prediction (the description of the future). It is necessary to distinguish different types of predictions and forecasts. 1) The forecast can be done on a scientific basis, facts and is necessary for different spheres of human activity: economy, medicine, hydrometeorology, policy, sociology, sport, etc. 2) Other type of forecast astrological - is not scientific, but is demanded not less than above-named, and also on all social levels, up to heads of states and royal persons.

It is represented that these types of predictive discourses have own structural, substantial, communicative, pragmatical characteristics, and, therefore, different ways of language representation. So there is a certain similarity between them based on general described temporary space: the future in relation to the moment of forecast creation (prediction). Thus, we see our task in comprehensive study of these types of discourses.

Let's consider some aspects of an astrological discourse. Representatives of astrology apply for scientific character and forecasts reliability and defend a scientific status of an astrology. Really, the astrology has its own concept and theory, a conceptual framework, terminology, organization principles, and also, according to her representatives, is based on facts and observations. All this reflects as it was already noted, in a special discourse which specific requires special language expression means on different language levels.

English-speaking astrological discourse, in our opinion, includes a corpus, created during different periods of human history which possess certain characteristics directed on impact on the person having a certain intention: to know the future. Based on provisions of I.R.Galperin, we consider an astrological text as a language unit finished in structural and semantic sense containing information about the future or the facts influencing the future presented by various language means and information has a certain structure varying depending on pragmatical installation and is realized in a form of oral or written text [Galperin 1981].

The description of an astrological discourse as any other type of a discourse, assumes the characteristic of its standard participants, a chronotope, purposes, strategies, case texts, discursive formulas [Karasik 2002; Deyk van 1989;].

Certainly, the prediction is a communicative event in which specific participants are involved. It is also necessary to notice that a key concept for a discourse analysis is discursive practice. Discursive practices which were introduced into terminological circulation by M. Foucault are considered as some "languagelike, i.e. similar to language by its structuring ability mechanisms of "knowledge and culture" [Foucault 1996]. As N. Ferklaf notes, discursive practices are connected with different parts of text functioning. Besides, the following fact attracts attention that texts are integrated into system of social (public) conditions of production and consumption [Faireclough 1995: 58]. Thus, an astrological discourse can be described according to the following scheme: 


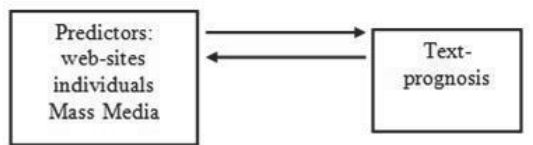

Genre conventions

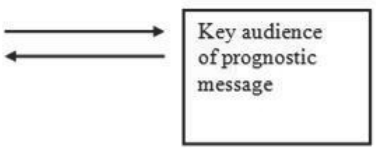

Reading/Decoding

Figure 1. Discourse-analysis of astrology

In a considered discourse authors of texts-forecasts are predictors, astrologers, clairvoyants, etc. In English they are presented by various and wide semantic-stylistic paradigm of words: predictor, forecaster, foreboder, astrologer, foreteller, fortune-teller, soothsayer, seer, diviner, prophesier, prophet, presager, oracle, augur, chiromantist, chiromancer, palmist, numerologist, clairvoyant, psychic, cabbalist, etc. General sema unites these words [speaker about future]. Certainly, a keyword is a predictor which does not have specifying semantic component, stylistically neutral and, therefore, capable to designate any person speaking about events in the future based on real, scientific facts, not having truly scientific data. The nominations foreteller, fortune-teller, forecaster, are close in semantic structure to predictor, however they are more associated with predictors who are based on extrasensory abilities more. Besides, they are marked stylistically as they are rather characteristic for colloquial and household communication.

Distinctive semantic sign is sema [information source] which is represented as follows in the nominations: astronomical bodies, stars, their arrangement (astrologer); numbers, figures (numerologist); individual spiritual abilities of the predictor (fortune-teller, seer, clairvoyant, psychic, oracle, medium, spiritualist), spiritual abilities granted by God (prophesier, prophet). As it was noted above, religious and esoteric discourses, despite some common features, differ in a number of essential signs, the words prophesier, prophet are only indirectly connected with an esoteric discourse, and at times they are opposed to it. So, for an astrological discourse, first of all, the nomination of authors: predictor, astrologer, foreteller, fortune-teller, soothsayer are relevant. The nominations clairvoyant, psychic, oracle, medium, spiritualist, augur have a book, archaic connotation, they are not opposed and do not contradict to astrological nominations and can be used in parallel as often author combines abilities to interpret celestial bodies arrangement and spiritual, extrasensory abilities.

An astrologer identity is shrouded by mystical, magic aura and is important to percept his information. The perception is influenced by historical authority, a world fame (Nostradamus, Vanga), popularity on a country scale (Globa), little-known, but mysterious names mentioned in horoscopes (Donna, Heather). However, not always these discourse participants and creators of texts-forecasts are known to their reader, a consumer of relevant information. As we see from the scheme, in modern world the main sources of texts-forecasts are mass media, websites. Frequently a direct author of the forecast is unknown to the reader, information is provided in mass media and on websites and anonymous predictors are hidden. In astrological texts-forecasts (horoscopes) certain discursive strategy are used which are usually presented in two blocks: 1) speech influence, i.e. strategy of messages forecasts creation (horoscopes) which have special abilities to influence consciousness and behavior of target audience, and 2) texts-forming, i.e. the strategy forming and organizing an order of material supply in the text. These strategy and tactics are realized by means of certain techniques which bank is quite various and is not assigned strictly to any certain tactics. So, one of the approaches is authoritative intermediary involvement that is also called by the English word testimonial, i.e. "recommendation, characteristic". For an astrologer such authoritative intermediaries are celestial bodies influencing the course of events on the earth:

(1) Planets in this sign will often reflect a vulnerable character and oversensitive nature. There is also a possessive streak, and a tendency to be emotionally smothering.

(2) Expect powerful shifts to occur between March (Jupiter joins Uranus in your career sector) and May (six planets line up at the top of your horoscope). Dare yourself to take your greatest career risks during late January until the end of May, which is when Jupiter peaks at the top of your horoscope.

The target audience of the predictive message is presented very widely and for authors of forecasts it makes a big group of people who are interested in their future, or a specific individual, the client, a patient with certain inquiry. However even if people address to astrologers massively, they "send" their patients to certain groups according to definite criteria. So, in the most widespread zodiac horoscope, which is universal for many cultures of the modern world, there are 12 groups: aries, taurus, gemini, cancer, leo, virgo, libra, scorpio, sagittarius, capricorn, quarius, pisces. In each group patients can be concretized: Cancer-man, Cancerwoman, Cancer-child or they can be generalized (Cancerians): 
(3) The Cancer-child is the homebody of the Zodiac, shy and sensitive sort who would rather play in their room than face the brave new world.

(4) Cancerians are very creative and love family, qualities that can lead to bliss in the workplace if properly merged.

However, the majority of astrological sites contain an appeal to individual, personal and the most exact horoscope.

(5) To receive individual daily astroweather forecasts, join Donna site ...

Couples' Composite: Your Life Together

(6) Discover the dynamics of your composite chart, which represents the fusion of your combined energies! Check out Heather's blog, "Cosmos Love" - here!

As we see, horoscope specification is offered also for individuals in couples, their compatibility. The individual address is one of the major texts-forming tactics of horoscopes authors which form and organize an order of material supply in the text and it is accurately expressed in them by means of various language means, such as pronouns of the 2nd person, modal and idiomatic expressions, various stylistic and syntactic receptions urged to influence a patient. A framework of the article does not allow to consider them in detail. The description of all corpus of language influence means on a horoscope consumer requires special attention and represents itself a research prospect.

During the research of this discourse type one more important task, in our opinion, is identification and description of main nominative tools which call key concepts of an esoteric discourse. Some of them were already mentioned above. Here we refer areas names, kinds of an esoteric sphere, names of this discourse type participants, and also actions which are done by them. As research shows, the paradigm of these names in English is wide and various. It represents a certain person or a group of people (1) involved in a certain type of esoteric activity (2) and who are carrying out certain actions (3). In the course of this activity a communicative strategy (a chain of communicative tactical steps) is developed directed on global communication purpose achievement. Complicated relations of these components also makes a thing that T. van Deyk defines as a discourse [1]. V. I. Karasik considers communication participants as the most important categories of a discourse, their status and role and situational and communicative characteristics, communication conditions, communication area, communication environment, communication ways [2, pages 270-287].

Let's consider nominative units of an esoteric discourse from the point of view of their etymology, semantics and word formation. These aspects, in our opinion, promote the disclosure of esoteric discourse certain essential characteristics. We refer the verbs calling actions of esoteric character to its nominations (to predict, foretell, forecast, foresee, forebode, prophesy, etc.), and the nouns calling producers of these actions (predictor, foreteller, forecaster, prophet, soothsayer, clairvoyant, augur, etc.), and also the nouns calling this or that esoteric process (esoterica, divination, augury, prognostication, prognosis, prudence, foresight, chiromancy, pegomancy, palmistry, presage, clairvoyance, astrology, foreboding, presentiment, cabbala, etc.), the nouns designating a certain sign, a symbol, an omen of events (omen, prodigy, presage, portent, oracle, hap, etc.).

Etymological analysis shows that among esoteric discourse nominations there are both original English, and borrowed lexical units, borrowed lexical units prevail. First of all we note that key, uniting term esoterica (esoteric) is borrowed and goes back to the Greek esoterikos (something, belonging to an interior where eso - 'within'). The majority of loans has a Romance origin, both Latin, and French. From these languages also word-formation samples of many considered lexical units are borrowed. Let's show told by the concrete language facts.

A number of esoteric discourse nominations is presented by the words, mainly, borrowed, which have simple morphological structure: psychic, oracle, medium, augur, omen, cabbala, cabal, etc.

\section{Results}

Semantics and nominations etymology is quite transparent and clear. The majority of predictors names represent the derivatives from the words, nominating predictions action, in the same row the name of the most esoteric process is connected, forming paradigms of esoteric nominations:

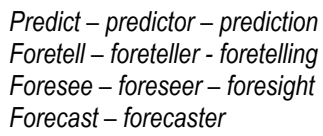

The most widespread word-formation model among considered units is prefix combination with semantics of 
precedence and a word root with the meaning of speaking in most cases, and also with the meaning of vision, feeling, knowledge, etc. This model is typical both for borrowed, and original words, perhaps, they loaned it from Romance origin. For example, it is a structure of Latin loan, the verb predict:

Lat. praedicere from prae "before" + dicere "to say".

We can see that key, dominating among other esoteric actions is a word predict which does not have connotations, it is stylistically neutral and, therefore, it is able to designate a wide range of actions which are based both on real, scientific facts, and on facts which don't have scientific data. It is remarkable that in dictionaries its initial value is connected with scientific prediction ability and is dated by 1620 .

Latin prefix "pre -" is widely presented in lexical units nominating esoteric concepts. We observe it in lexical units presage (v), presage (n), presentiment, premonition and some other:

Presage from prae- "before" + sagus "prophetic" correlated to sagire "perceive" (late 14v.)

Presentiment (n.) from French 'presentiment', middle-French 'pressentir' "have a presentiment" from L. præsentire: præ "before" + sentire "perceive, feel".

Numerous lexical units with a prefix of a Greek-Latin origin "are presented to pro -", meaning "before", "beforehand": prognosis, prognostication, prodigy, prophet, etc. So, prognosis goes back to Greek Prognosis: pro"before" + gignoskein (gnostic) of "come to know".

Prophet is dated by $12^{\text {th }}$ century and ascends to O.Fr. prophete ( $11^{\text {th }}$ century), L. propheta, and Gk. prophetes "prophet", originally it has a religious root, from pro-+ a root from phanai "to speak", from PIE * bha-"speak". Not religious meaning Prophet is fixed from 1848. The verb designating the corresponding action of prophesy is included in this lexical nest (late $14^{\text {th }}$ century.), from O.Fr. prophecier (mid-13 $3^{\text {th }}$ century), and a noun prophecy which defines function prophet, prophecy process.

Original lexical units of the considered group have similar morphological structure:

Fore+tell, fore+see, fore+cast, fore+bode.

Taking into consideration that Russian lexical units to foresee, predict, have a presentiment, to presage are formed in a similar way, it is possible to speak about universality of this word formation model of esoteric semantics lexical units for Indo-European languages, and consequently, concepts have deep roots in cultures of European people.

Unlike above-mentioned units esoteric nominations of French origin clairvoyant (n.) - clairvoyant (adj.) clairvoyance (n.) are formed by composition (from French clair (see clear) + voyant "seeing"). It is also possible to note their incomplete assimilation. In this row we do not find the nomination of action though in French to formation these words we use the verb (voir). The earliest loan in this row, according to etymological lexicographic sources, is an adjective clairvoyant designating quality, property of the person "clearly to see" which became further his name clairvoyant (n.) Along with these loans in an English esoteric discourse the original noun seer functions with simple morphological structure and very capacious semantics. Seer designates not simply someone who sees, but the one who sees something that others can't see.

The big group of nominations of an English-speaking esoteric discourse is made by the nouns formed by means of a suffix - mancy. They designate different types of esoteric practices, reflecting different abilities of their performers based on different signs, symbols, events, etc., which have different sources of information. According to lexicographic sources a suffixal morpheme - mancy has Greek-Latin roots: Lat. - mantia, Gk manteia that meant "oracle, prediction ", and also the root of "mantis" meaning "seer, predictor" and correlated to "mania" - mania, madness. In modern English the most common nomination of the most known and popular esoteric spheres astrology had originally an analog of astromancy (1650).

The lexical unit of "chiromancy" designating the esoteric process based on an arrangement of lines on a hand to interpret events, character, person destiny is well-known (from late Greek kheiro -"hand"). Also the synonym "palmistry" is used.

Other sources of information, bases of esoteric practices, reflected in nominations, are very various. For example, water has always had special characteristics, including mystical:

pegomancy - a prediction by fountains (dates to 1727) from Gk. pege "fountain, spring" + manteia "oracle, divination";

lecanomancy - a prediction by water observation and its state in container (a basin, a bathtub) (1600) from Gk. lekane "dish-pan" + - mancy.

To describe and predict events, esoterics also use animals, their behavior. So, myomancy means prediction by mice movements (from Gk. myo, and also OE mys, 1725);

Alectryomanc means a prediction by a cock and corn kernels where the first element comes from the Greek alektryon "cock". 
Mirror is always used as a symbol and magic attribute. Esoteric practice based on mirror use is designated by catoptromancy noun from Gk. katoptron "mirror" (1610).

Esoteric area which is traditionally designated in modern English by the word numerology and based on numbers and their meanings has also designation of arithmancy - prediction by means of figures (1570).

Besides, predictions nominations include nominations of communication with dead spirits (necromancy, sciomancy), predictions of earth signs (geomancy), prediction of the book, opening the page simultaneously (bibliomancy), prediction of ashes (tephromancy 1650) - from Gk. tephra "ashes" and some other. aeromancy.

It is remarkable that in Middle English a weather forecast was also designated by the word with a suffix - mancy:

\section{Conclusion}

In summary it should be noted that considered lexical units have special stylistic coloring, many of them have an archaism shade. However specifics of esoteric sphere is that archaism, an antiquity shade give it a special color, mystery, mark it as different from habitual, real, terrestrial, allow to influence a personality. Therefore some of described lexical units became outdated, and others again are starting to be used together with reviving types of esoteric actions and modern person's keen interest in them. The implemented analysis is based on lexicographic sources. In long term perspective it is planned to research discursive and text potential of esoteric discourse nominations on the material of modern English, and nominations place in an English-speaking esoteric concept sphere.

\section{References}

Galperin I.R. Text as an object of linguistic research. - Moscow, 1981.

Deyk T.A. Van Yazyk. Knowledge. Communication. - Moscow: Progress, 1989

Karasik V. I. Language circle: personality, concepts, discourse. Volgograd, "Peremena", 2002

Kashkin V. B. Introduction to a discourse theory. Moscow: "East book", 2010. 152 pages.

Knyazeva A. A. Texts about future prediction as a type of predictive texts //News of RGPI in the name of A.I. Herzen. - Saint Petersburg: Book house, 2009. No. 114. - Page 207-212.

Makarov M. L. Basic concepts of discourse theory. - Moscow: ITGDK "Gnozis", 2003. - 280 pages.

Savitskayte E.R. Discursive characteristics of predictive texts (on material of German horoscopes) / Autoabstract, Candidate of Philology, Voronezh, 2006

Stoykovich G. V., Klyushina A.M. Categorial and not categorial means of passivity expression in English scientific, art and political discourses. - The monograph // under scientific edition of Doctor of Pedagogics, M.P. Nechayev. - Expert and methodical center, Cheboksary, 2014. - 65 pages.

Foucault M. Archeology of knowledge. Moscow, 1996

Faireclough N.Critical. Discourse. Analysis. London: Longman, 1995 http://www.findyourfate.com/astrology_news/astrology-news.htm http://www.etymonline.com/ 